\title{
A Psychologist on the Step-down Coronary Care Unit
}

\section{Robert Allan}

Division of Cardiology, Weill Cornell Medical College, New York, NY, USA

The phone rang at 2:30 a.m. "I'm calling to discuss my platelets," the voice at the other end stated clearly. Mr. S had been a patient of my mentor, cardiologist Stephen Scheidt, who brought me to Weill Cornell Medical Center/New York-Presbyterian Hospital and graciously shared his office for 25 years. Dr. Scheidt died several years ago and I felt a special bond with Mr. S because of the connection. We met the day before on the step-down Coronary Care Unit (CCU) and I had encouraged him to call if he was distraught. I was certain Mr. S was not just calling about his platelets and he seemed reassured that someone was there for him in the middle of the night. Subsequently, I treated Mr. S over several hospitalizations. Mr. S's case, and several that follow, are examples of the non-traditional health-promoting roles suggested by my work on the step-down CCU.

The field of cardiac psychology, also known as behavioral cardiology and psychocardiology, began in 1959 when two cardiologists, Meyer Friedman and Ray Rosenman invented the "Type A behavior pattern," which is characterized by easily aroused anger (free floating hostility) and time pressure (doing too much in too little time). Early research linked type A behavior with an increased risk of myocardial infarction (MI) [1]. Since then, a substantial empirical evidence base has evolved informing the field. A PubMed search of the terms "psychosocial factors and cardiovascular disease" currently yields more than 50,000 citations.

Research now links such factors as depression, social isolation, anxiety, and anger with both the onset and poor treatment outcome of coronary heart disease (CHD). A meta-analysis of 893,500 initially healthy subjects reported that depression is a risk factor for both MI and CHD [2], while another meta-analysis of 317,540 subjects determined that depression is a risk factor for non-fatal and fatal stroke [3]. In 2014, an expert panel convened by the American Heart Association recommended that depression be elevated to risk factor status for patients with acute coronary syndrome [4]. In a meta-analysis with $2,017,276$ subjects, anxiety was associated with an elevated risk of cardiovascular mortality, CHD, stroke, and heart failure [5]. A metaanalysis of loneliness and social isolation reported that deficiencies in social relationships were associated with an increased risk of developing $\mathrm{CHD}$ and stroke [6]. Anger has been shown to increase risk of CHD in healthy individuals and cardiac patients [7] as well as "trigger" MI, stroke, intracranial aneurism rupture, and ventricular arrhythmia [8]. On a more positive note, optimism has been found to be a robust protective factor against cardiovascular disease [9].

In stark contrast to these data, the most recent Cochrane review [10] contained only 35 clinical trials attempting to treat psychosocial risk factors, thereby reducing cardiac morbidity and mortality. The 35 trials contained 10,703 subjects with CHD. The population was comprised of mostly men (median $77.0 \%$ ), patients post-MI (mean $65.7 \%$ ), or after undergoing a revascularization procedure (mean $27.4 \%$ ). The mean age of participants ranged from 53 to 67 years old.
Despite the vast epidemiological evidence base linking adverse psychosocial factors to the onset and poor outcome from CHD, there are scarcely any healthcare practitioners helping cardiac patients with psychosocial issues.

Although I have conducted cardiac support groups over several decades, it has only been in the past few years that I have become a part of the treatment team on the step-down CCU. My work was initially championed by Erica Cargill Jones, then Director of the Inpatient Telemetry Unit. Dr. Jones is an extraordinarily intelligent and sensitive human being who identified patients in need of psychological intervention with uncanny accuracy. We worked together for about a year, at which time she took another position at the Medical Center. Since then, the step-down unit has had attending cardiologists who rotate every two weeks, a dozen or so in all. It has been quite a challenge to prove my worth. What is a psychologist doing on a step-down Coronary Care Unit? However, I have apparently proved my mettle as this cadre of attendings, as well as residents and fellows, have come to appreciate our patient's emotional needs and now routinely make referrals to me.

The vast majority of patients, however, do not require psychological care. Liaison psychiatry provides services for those with serious psychiatric disorders that require pharmacologic treatment. On the unit, there is little opportunity for patients to discuss their often painful and sometimes complex emotional reactions to their diagnosis of heart disease. The attending cardiologist and healthcare team identify patients who might benefit from a "chat with a cardiac psychologist." To avoid stigma, it is often necessary to assure patients they have not been referred because they are "crazy," but rather, because they might benefit from talking about their experience and emotions, since being in the hospital with heart disease can be very stressful.

Moreover, recent Medicare guidelines penalize hospitals with hefty fines for readmission within 30 days of MI and heart failure. Intervention with "frequent fliers," patients with repeated readmissions, some of which might be attributable to treatable psychosocial issues, might reduce the burden for both patients and hospitals alike. Mr. S had a habit of not taking his medications as directed once he left the hospital. I took it upon myself to reach out by phone after he was discharged to try to change this pattern. Curiously, while we had excellent rapport in the hospital, he brushed me off once he was home.

Correspondence to: Robert Allan, $\mathrm{PhD}$, Division of Cardiology, Weill Cornell Medical College, New York, NY, USA, E-mail: cardiacpsych@msn.com

Key words: cardiac psychology, behavioral cardiology, coronary heart disease, cardiovascular disease

Received: December 06, 2017; Accepted: December 25, 2017; Published: January 02, 2018 
Initially, my role on the step-down unit was to be there for the patient, to listen empathically. Experience soon suggested modifying the traditional therapist role to become a sort of "professional support system." Early on, I discovered that many patients needed assistance with important practical matters. For instance, I went to the bank for a patient to pick up checks so he didn't miss a rent payment. The manager commented that he often sat in the bank for hours after his wife died. This patient had no friends or relatives and I became his "legs" outside the hospital. He was worried about the check for his rent stabilized, apartment reaching the management company on time. After 10 days it had not arrived and he was panicked about being evicted - as well as distrustful and furious at me. A week later when the check was finally received we both breathed a sigh of relief. A young woman with a grave illness was abandoned by her family - her relatives would barely speak to her. She stated, "that's just the way it is in my family." She craved Snickers bars and the newspaper, which I brought her every day. I began lending CD players and headphones so patients could listen to music and even provided some CDs of my own music. Music helps patients pass the time more enjoyably. In short, I have come to define my role broadly as someone who can listen and help patients process emotional issues as well as be helpful with practical matters.

In contemporary cardiac care, a visit to the doctor for chest pains followed by an elective angioplasty and stent placement have become commonplace. In an informal survey over many years, angioplasty is most often judged less painful and anxiety provoking than going to the dentist for a root canal. Because patients live much longer these days with advanced heart disease, surviving a life threatening heart attack or living with the symptoms of chronic heart failure increasingly trigger distress and complex emotional reactions. The hospital can also be a very lonely place, especially for those who do not have a strong social support network. One patient's apartment burned down while he was in the hospital. His relatives all lived in Europe and he had only a young nephew in the U.S. With no one to talk to he was immensely comforted by our conversations and I helped him plan a strategy for managing this challenging situation. Fortunately, our social workers were able to help him find a place to live.

Young patients often have strong negative reactions to their illness because it is the last thing they ever imagined. Fear, anxiety, depression, anger, and resentment are commonplace. John is an athletic, handsome 28-year-old. I first saw him doing laps around the step-down unit in an unsuccessful effort to ward off his anxiety. In perfect health until he developed chest pains a few weeks before, John was terrified while awaiting his diagnosis. There was a suspicion of a thymoma requiring cardiothoracic surgery. Was he going to die? I was able to reassure John that he was young, in excellent overall health, and he was being treated in a great hospital by a superb surgeon. He had refused the suggestion by others to take a tranquilizer. When he took it at my urging he felt much better. Later, I introduced John to meditation, which he had never tried, although a book on the subject was on his nightstand. John got immediate benefit as well as an anti-anxiety tool to take home with him after his successful surgery. He was eager to follow up as an outpatient and we met for several sessions. He soon returned to his high level of functioning.

The former fireman had heroically carried an unconscious survivor over his shoulders and down 10 flights of stairs during the World Trade Center disaster. After 911 he suffered many illnesses including a heart attack, 9 stents, coronary artery bypass surgery, heart failure, chronic obstructive pulmonary disease, and diabetes. I was pleasantly surprised when the attending cardiologist on the step-down CCU said the patient had asked to speak to me on this, his third admission over the past year.

Earlier, we had established easy rapport based around "New Yawk City" banter. The patient had been invited to try one of my outpatient cardiac support groups, but he lived too far away to make attendance practical. When I saw him at bedside the fire fighter explained, "In 2005 I had a normal nuclear stress test and my cardiologist told me I was fine, but I didn't feel right. Two days later I had a heart attack. I feel exactly the same way now. But I want to go home. My wife told me its ok because if I die the family will be taken care of for a very long time." It seemed the patient was implying that if he was discharged and died, his family would sue the Medical Center for malpractice. I carefully tested the limits to be sure I was hearing correctly and immediately informed the attending cardiologist.

On entering the to the patient's room, the cardiologist and I were met with "I'm going home today, no matter what you say. "When the cardiologist shared my conversation, the patient was enraged at me for violating his confidence. I explained that in cases of life or death it is my professional responsibility to share such vital information. A little while later I went back to see the patient alone and in a manner reminiscent of the movie, "The Godfather," he repeatedly wagged his finger at me, "You should'na done that," he said over and over again. His story then changed to "my wife was just joking," but the patient's premonition had alarmed the cardiologist who advised him that no one knows their body better than the patient himself. The cardiologist urged the fireman to undergo a cardiac catheterization and insisted that if he left the hospital prematurely it would have to be against medical advice. The catheterization proved unremarkable and the fireman was discharged intact - except for the belief in the infallibility of his intuition.

One morning the first person I encountered as I walked onto the unit was Dr. Evelyn Horn, Director of the hospital's Advanced Heart Failure program. She informed me that a woman I had been following over 3 hospitalizations during the past year was in the main CCU. Brenda is a highly emotional woman in her late 60's with advanced heart failure. We bonded, in part, because we had shared life experiences: she had performed as an actress and dancer during summers in the Adirondacks and I had worked as a musician in the Catskills. We met for extended sessions because she was socially isolated as well as a "frequent flyer." I made an extra effort to make a sincere human connection and was her only visitor on Christmas. The day before my chance encounter with Dr. Horn I had seen Brenda at a nearby nursing home and she looked dreadful. She was attached to an oxygen tank and her entire body was bloated from the accumulated fluids her highly compromised heart could no longer circulate. During our conversation I helped her understand that if she was to live there was no choice but to finally agree to undergo an alcohol ablation, the long recommended treatment she had been avoiding. Failing rapidly, Brenda had to be rushed to our CCU a few hours after our conversation.

It was agreed that I should be present at the signing of the informed consent form. This requirement can terrify patients as the rare negative consequences that might occur during the procedure, including death, are described. Brenda had backed out before. Due to our relationship of trust this time she moved forward. Afterwards, I was installed in the control room from where I would coach her. Wheeled into the procedure room on a gurney, Brenda was already conspicuously agitated and Dr. S. Chiu Wong, Director of the Cardiac Catheterization Laboratory, pointed to me and instructed a staff member to "put him in lead." Once outfitted with radiation shielding, I was able to enter the lab and remain close to Brenda. Several times during the long procedure 
she became highly agitated and could not remain still. The sound of a familiar, calming voice helped her get through the ordeal. Within 24 hours Brenda's heart was remarkably improved and now a year later she is doing quite well. According to Dr. Horn, I saved Brenda's life by "meeting her needs." This is always a delicate situation with patients who are having difficulty accepting a treatment recommendation. A psychologist must "be there" for the patient and not be seen as a coercive extension of the medical team trying to convince them to undergo an unwanted procedure. My role is to help the patient make the right decision for themself and not let fear and distress, but their rational mind, make that decision.

Back to Mr. S. He kept returning to the hospital over shorter and shorter intervals. Dr. Scheidt was a man of science and he encouraged an inquiring and independent spirit in many of his patients. This backfired with Mr. S. who insisted on receiving his daily lab reports which his doctors patiently reviewed with him. Sadly, he often challenged their recommendations. He refused a cardiac catheterization, which might have determined that he was a candidate for advanced heart failure treatment. Mr. S readily acknowledged that he did not take his medications "exactly as directed" out of the hospital because he didn't like the way they made him feel. The staff warned that he was risking irreversible damage to his body and death. Ultimately, he returned to the hospital with liver and kidney failure. While awaiting hospice placement one of his friends keeping bedside vigil confided that he never took any medication outside of the hospital. Sadly, sometimes my best efforts fail.

But once in a great while my intervention has resulted in profound and rapid change. This occurred in the case of a wife who blamed her husband for needing a heart transplant because he had not exercised enough. When I explained that she was confusing coronary heart disease, which often has a major lifestyle component, with her husband's cardiomyopathy, sometimes a genetic disorder and which may have had nothing to do with his sedentary ways, their relationship was transformed. He stated that my intervention was "magic," the only time in my long career anyone has made such a flattering comment.

Have I reduced 30 day readmissions? What I have learned is that this is an extremely complex issue and there will not be a few simple solutions that can be described in a treatment manual. Even the most apparently simple case can turn out to be different from what it first seems. One indigent "frequent flyer" would routinely run out of pills, precipitating a medical emergency and hospitalization. After I arranged to provide extra medication on discharge, I went into his room to deliver the good news only to be met with a deep grunt. He soon told a resident, "Don't ever let that psychologist in here again." I came to understand this fellow apparently liked being in the hospital, enjoyed the care and attention, and savored the regularly prepared meals.

The problem of rapid and frequent readmission is under study at major medical centers around the country. I hope that my experience will help inform the field of the complexity of this issue, which will not be dealt with effectively without better individualized understanding of the person who is the patient and not just their medical diagnosis. We now have abundant evidence that psychosocial factors contribute to heart disease and the success of medically prescribed treatments. We now need to figure out how to treat these factors in order to improve patients' quality of life and achieve the holy grail of cardiac psychology, to further reduce cardiac morbidity and mortality.

\section{References}

1. Rosenman RH, Brand RJ, Jenkins D, Friedman M, Straus R, et al. (1975) Coronary heart disease in the Western Collaborative Group Study. Final follow- up experience of 8 1/2 years. JAMA 233: 872-877. [Crossref]

2. Gan Y, Gong Y, Tong X, Sun H, Cong Y, et al. (2014) Depression and the risk of coronary heart disease: a meta-analysis of prospective cohort studies. BMC Psychiatry 14: 371. [Crossref]

3. Pan A, Sun Q, Okereje Ol, Rexrode, KM, Hu FB (2011) Depression and risk of stroke morbidity and mortality: a meta-analysis and systematic review. JAMA 306: 12411249. [Crossref]

4. Lichtman JH, Froelicher ES, Blumenthal JA, Carney RM, Doering LV, et al. (2014) Depression as a Risk Factor for Poor Prognosis Among Patients With Acute Coronary Syndrome: Systematic Review and Recommendations. Circulation 129: 1350-1369. [Crossref]

5. Emdin CA, Odutayo A, Wong CX, Tran J, Hsiao AJ, et al. (2016) Meta-analysis of anxiety as a risk factor for cardiovascular disease. Am J Cardiol 118: 511-519. [Crossref]

6. Valtorta NK, Kanaan M, Gilbody S, Ronzi S, Hanratty B (2016) Loneliness and socia isolation as risk factors for coronary heart disease and stroke: systematic review and meta-analysis of longitudinal observational studies. Heart 102: 1009-1016.

7. Chida Y, Steptoe A (2009) The association of anger and hostility with future coronary heart disease: a meta-analytic review of prospective evidence. J Am Coll Cardiol 53: 936-946. [Crossref]

8. Mostofsky E, Penner EA, Mittleman MA (2014) Outbursts of anger as a trigger of acute cardiovascular events: a systematic review and meta-analysis Euro Heart $J 35$ : 1404-1410. [Crossref]

9. Boehm JK, Kubzansky LD (2012) The heart's content: the association between positive psychological well-being and cardiovascular health. Psychol Bull 138: 655691. [Crossref]

10. Richards SH, Anderson L, Jenkinson CE, Whalley B, Rees K, et al. (2017) Psychological interventions for coronary heart disease: Cochrane systematic review and meta-analysis. Eur J Prev Cardiol. [Crossref]

Copyright: (C2018 Allan R. This is an open-access article distributed under the terms of the Creative Commons Attribution License, which permits unrestricted use, distribution, and reproduction in any medium, provided the original author and source are credited. 